\title{
MAT_er.LAB, the Interdisciplinary Playground Where Science Means Personal Growth
}

\author{
Sabine Lettmann*, Zoë Hillyard and Beth White \\ Institute of Jewellery, Fashion and Textiles, Birmingham City University, UK
}

*Corresponding author: Sabine Lettmann, Senior Lecturer, Institute of Jewellery, Fashion and Textiles, Birmingham City University, 5 Cardigan Street, Birmingham, B4 7BD, UK.

Received Date: April 14, 2020

Published Date: May 05, 2020

\begin{abstract}
The fashion industry reacts to the current coronavirus pandemic highlighting a failing system lacking humanity. Large corporations are refusing to pay for orders that they have placed leaving the most vulnerable within the production chain paying the price. This raises the urgent question; how and when will the industry step up and change for the better? Therefore, it needs to be asked in which areas Higher Education can tackle the existing lack of responsibility and how a collaborative and social mind-set can be ignited. How can an environment where students aim to work collectively and interdisciplinary be created? MAT_er.LAB, an initiative developed by academics and technicians from the Faculty of Art, Design and Media at Birmingham City University (BCU), offers an experimental environment for students of all year groups and all courses to cross pollinate their overall learning outcome through engagement with the unknown. Detached from the curriculum, the laboratory creates a playful approach to investigate, challenge and explore whilst social skills and circular mind-sets are enhanced. Brought back into regular modules these attributes help to shape a new generation of creatives valuing a more inclusive and sharing way of working.
\end{abstract}

Keywords: Interdisciplinary Learning; Circular economy; Design thinking; Biodesign

\section{Background of the Study}

April 2020. The world is in a state of shock, everything currently seems upside down. Yet, we don't know how the fashion industry and all linked sectors will react to the global outbreak of the coronavirus in the long run. With more weeks of lockdown to come, everyone, including Higher Education, is offered time to reflect on teaching, develop visions for an ever-changing future and fill an almost blank page of concepts with what we align to our core values for life. The disruption of what we called normality is an opportunity to slow down and create a new substantial base for a healthy society in which fashion does play a role but becomes an expression of inclusivity and collaboration on multidimensional levels, spanning mindful structures around the globe.

Current global developments differ from country to country, from society to society. Looking at the manufacturing and even disposal situation in Asia or Africa the heart of our fashion industry is already run on minimal wages and poor living conditions. Facing the dramatic consequences from this pandemic, it is likely this will extend further. So much of the vulnerability of these structures relies on how we value fashion and textiles as educators, brands and consumers. It painfully reveals how isolated parts of the supply chain still are and how detached from the processes of designing, making and dispose we remain when linear structures are followed, and the value of humans is neglected. The change in the fashion industry inevitably has to happen. If not now, then when? Disconnection from the supply chain can only be bridged with awareness for existing problems and adopting holistic approaches to find solutions on a broader scale. Taking into account that change is also driven by knowledge we need to consider where we missed chances in educating fashion design, fashion business and textile student's year on year, acknowledging the current system is also a reflection of what we have taught them.

In 2018 the Organization for Economic Co-operation and Development published the Learning Compass, their vision for the future of education in 2030. The OECD report [1] defines knowledge, skills, attitudes and values that learners need to fulfil their potential and contribute to the well-being of their communities and the planet. In detail, skills workers need to succeed rely heavily on their uniquely (so far) human capacity for creativity, responsibility and the ability to "learn to learn" throughout their life. Further soft 
skills such as empathy, self-awareness, respect for others and the ability to communicate are seen as essential, with classrooms and workplaces becoming more diverse in many ways.

How can a learning environment enhance these skills, aiming to educate for a labour market that will value the well-being of communities and the planet? What opportunities do we have to react to long-lasting challenges that come with uncertainty, at the same time addressing the potential negative mental impact students may experience within the current situation? How can a different type of teaching, one that embraces a future-forward mind-set help students to transfer a positive learning outcome into their own work? Obviously, curriculum content plays a major role in how students evaluate materials, concepts and design strategies. But above all stands the open mind-set Higher Education should be able to build, creating empowered individuals with the capacity to benefit societies all over the world. This leaves educational institutions with the challenge to ignite a holistic paradigm shift through embracing new frameworks and educational practice.

\section{Laboratory Structure Enhancing Circular Mind-Sets}

In autumn 2019 a group of academics and technicians at the Institute of Jewellery, Fashion and Textiles at Birmingham City University (BCU) developed MAT_er.LAB, an interdisciplinary project within the Faculty of Art, Design and Media, aiming to facilitate and accelerate collaborative learning. Instead of just being a laboratory as the name might indicate, this initiative is far more. It is an unconventional playground aiming to explore not only materials, but also collective design and personal growth.

Cooperation with colleagues from KEA University in Copenhagen gave the team at BCU valuable insights into how to build a suitable supportive laboratory environment. This was then transferred into offering MAT_er.LAB as an on-going initiative to explore biomaterials enhancing a shift in how design is perceived and evaluated in general. The lab focuses on using waste, ordinary cooking ingredients and all kinds of plant-based sources nature offers, as a starting point to investigate material properties. Taking basic open-source recipes as a base, participants don't have to bring profound knowledge to be able to fully participate. Hence, their inhibition level remains low and engagement with the unknown is easily achieved.

Stepping away from familiar classroom settings where students remain amongst their peers and work on course-related projects, MAT_er.LAB invites students from across all year groups including Alumni to come together in a new context. Its fundament is the unknown blank page for all participants. Hierarchies dissolve, everyone is a beginner and therefore the fear of failure is low. Situated in the textile printing facilities, the lab has no constant space yet. It makes use of the existing textile workshop, providing participants with relevant basic structures like water access, cooking hobs and a drying unit, normally used for preparing screen printing frames. This set-up builds the benchmark for the lab itself as a place where everything is possible and successful outcome only depends on how participants take ownership and improvise by turning space and tasks into their own (Figures 1-3).
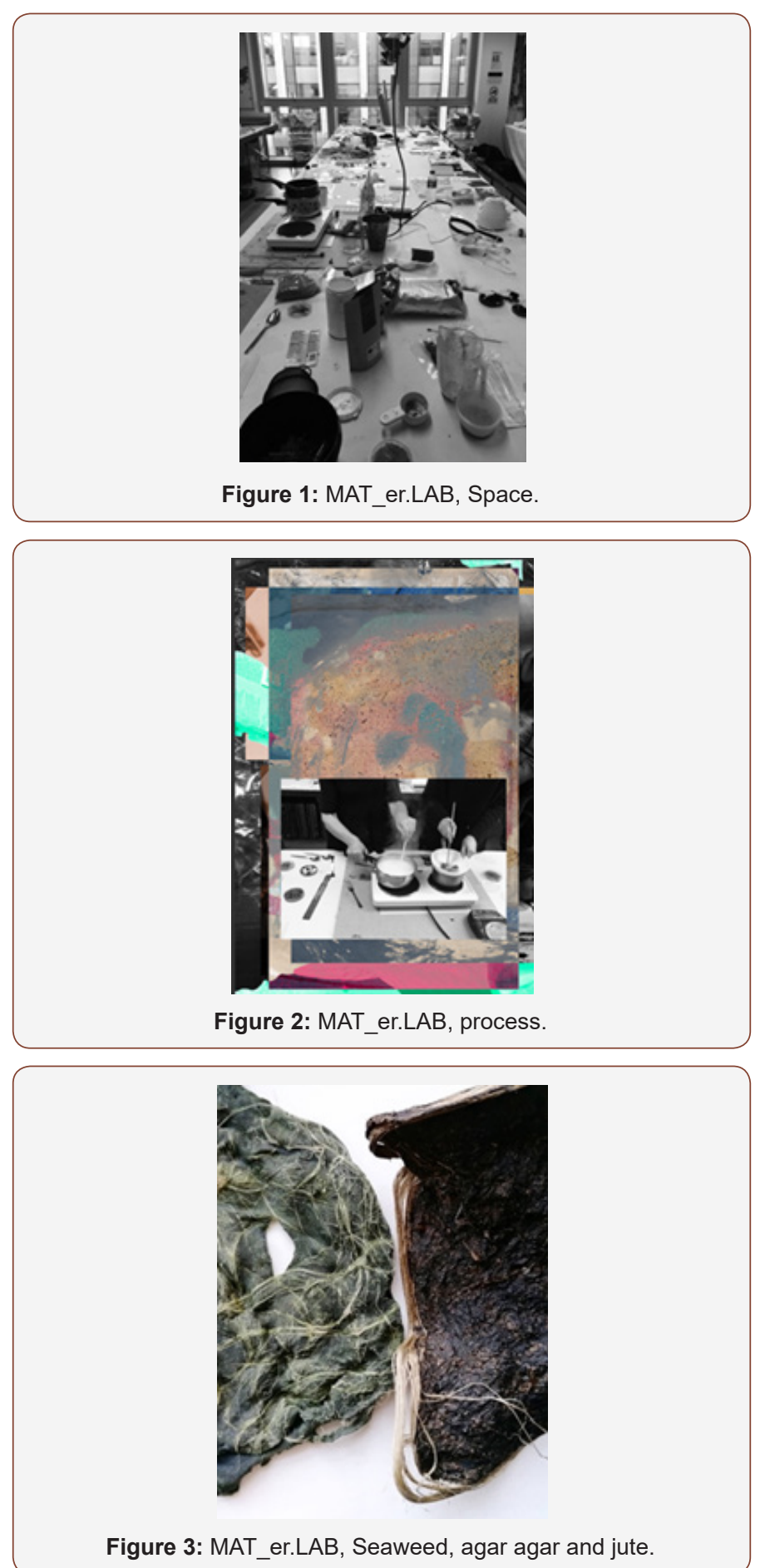

Through the careful balancing of ingredients, combined with the transformation on a molecular level brought about by rising to certain temperatures, new materials are created. Material properties such as flexibility, drape, strength and translucency can be controlled and refined. Lines of inquiry are often initiated by reflecting on material applications from the participants own design disciplines, furniture, fashion, textile designs. The questioning results in new alternatives - coffee leathers, jute furs, bio packaging and biodegradable beads. Many permutations are needed to refine material properties and establish detailed recipes that provide a 
level of consistency. Experimental lab journals capture the evolution of this knowledge and are tactile, investigative, uncensored working spaces that evidence conceptual focus, persistence and creative commitment. It is interesting to see traditional construction based skillsets like pattern cutting, weaving, knitting and stitching often being combined with the language of scientific experimentation. This embodies the 'STEAM' educational approach, adding 'Arts' to the British Government's STEM agenda.

Detached from their university programmes, student's selfinitiate meetings to experiment, self-regulating the experience of materials in its broadest sense with the potential of bringing multidimensional value back into individual courses. Without previous subject knowledge, they investigate in a placed-based learning environment gaining new skills through a playful approach of engaging with a new subject. According to the definition by Herodotou C, et al. [2] (2019) this requires an unpinned situation where students 'manage and respond to often unexpected circumstances with unexpected learning opportunities and outcomes likely to arise.' Furthermore, seen as 'a social form of learning, communication and collaboration are key skills developed, with a need to show sensitivity to local circumstances.'

Even though MAT_er.LAB is not positioned as the same sort of environment classic place-based learning methods refer to, it requires interaction and communication between participants to be able to work alongside each other or in teams. Presented as a laboratory, participants come with their own perception but without any expectation or pressure to fulfil module briefs or tasks. The flexibility of MAT_er.LABs laboratory equipment enables learners to customise an environment for themselves, optimising the potential for intuitive and authentic responses, either by individuals or teams. The seeming domesticity of many of the approaches and equipment provides a reassuring familiar point of departure. Following their personal interpretation of a laboratory, they investigate unknown areas of material practice without the necessity to reach a specific aim but embark on a new experience journey without having a destination. Although desirable, the freedom to try and enjoy experimenting doesn't usually take place within the academic practice simply due to student's goal, often mark driven mind-sets, and a lack of understanding the value behind play. As Stahel WR [3] states:

'Learning by doing is an integral part of the circular economy of craftsmen and SME. Spreading this knowledge -technical and economic- to class- and boardrooms, to academia and technical training institutions [...] is a major challenge in speeding up the transition to a circular industrial economy:

Therefore, new powerful opportunities beyond existing curricula introducing innovative ways of thinking can be a welcome addition to drive and increase change on a general level. Mind-sets aiming to find the much needed, circular strategies for a broad range of projects in regular modules from fashion to architecture can be ignited and supported (Figures 4\&5).
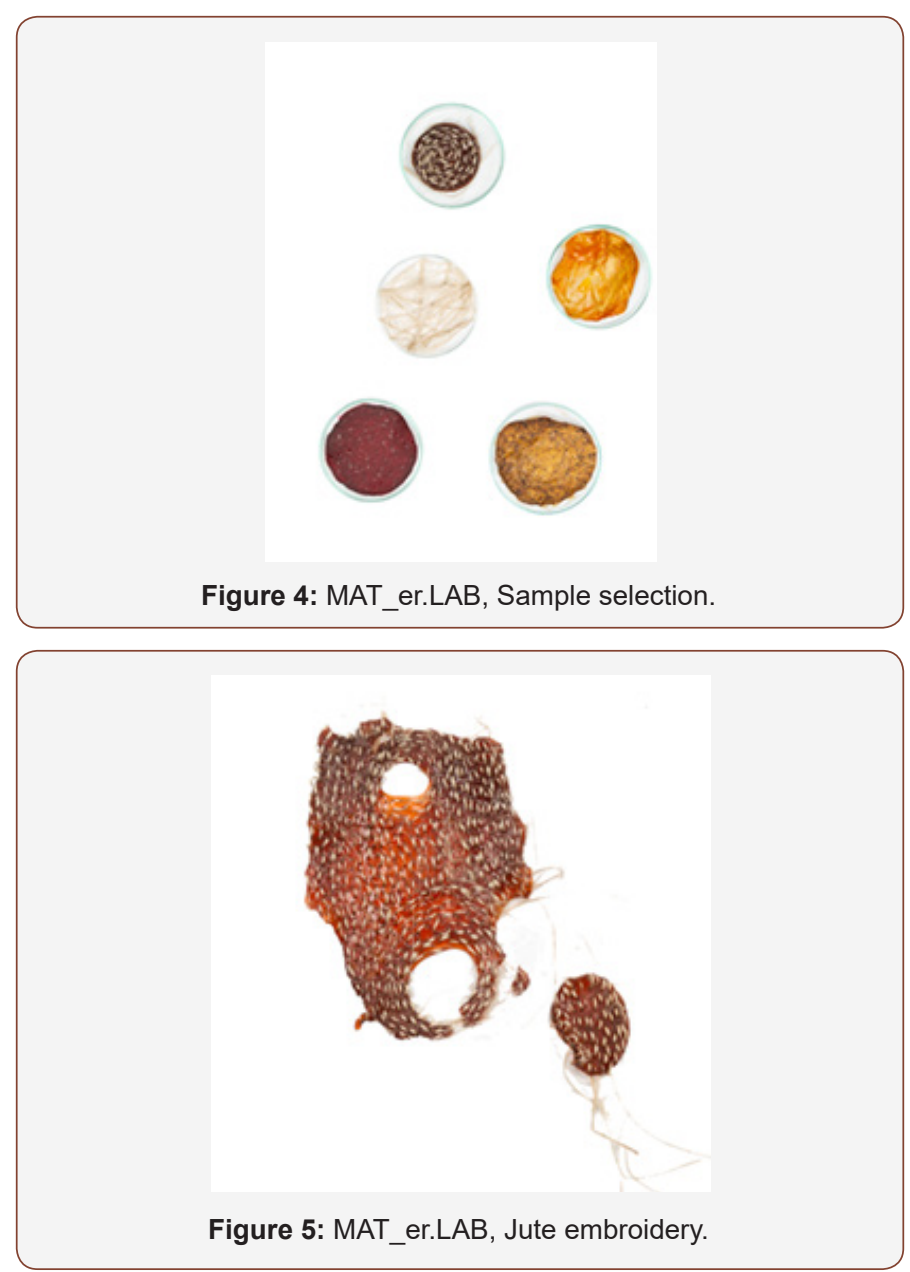

For many students, social isolation and lockdown strategies have severed them from workshop environments and equipment, forcing them to establish 'home studio' spaces to continue with their studies. Interestingly some have chosen to establish satellite MAT_er.LABs as part of this, due to the domestic and accessible nature of the equipment needed. Working independently, they are able to be connected to and supported by the wider network of biomaterial developers, adding as active agents to open-source knowledge banks.

\section{Design Thinking As the Core Experimentation Process}

With a clear emphasis on collaboration, the project aims to establish an environment that blends new knowledge generation with practical engagement, with learners encouraged to work together for a shared purpose whilst each individual having their personal journey through the project.

Coming from different backgrounds participants bring in their individual ideas and appetite for risk to play with the unknown. Having limited experimentation space, they all face the necessity to share equipment. They become part of teams where they inevitably start to communicate their understanding of a new, complex topic gaining collective knowledge. Observing others work, exchanging tips and recipes turns them into an intellectual circular society. Open source and fluctuating roles of learner and teacher come alike. Material components become the protagonists of this setting 
developing their own less controllable dynamic. Following von Glaserfeld E [4] (1987) this forced elasticity of social behaviour challenges student's ambitions and enables them to create a mutually understood language which here is the experiment itself.

Initiated as an open house the lab becomes the arc between disciplines. The more diverse the hosted groups are, the more the kaleidoscope of ideas is morphing with each individual joining. With its transgressed approach MAT_er.LAB creates its own studio culture, where autonomous decision making is replaced with collaborative work and lecturers as well as technicians are decentred.

Through practical engagement the learner juggles experimentation, nurturing ideas through different stages; solidifying, drying, shrinking, distorting and hardening. The rates of change vary, and ideas overlap. The trajectory is fuelled by curiosity and underpinned by logic, but the journey is not linear. Instead, in the sense of Dunne D, et al. [5] (2006) description of Design Thinking as cognitive processes that designers use, as opposed to the designed objects they produce, multiple strands of possibilities are developed with equally diverse potential. Initial intentions are sometimes realised, but more often not. The outcome results in more questions, but a growing awareness of which are the 'right' questions. This encourages open dialogue as ideas and knowledge bases between individuals or groups converge, overlap and diverge (Figures 6-8).
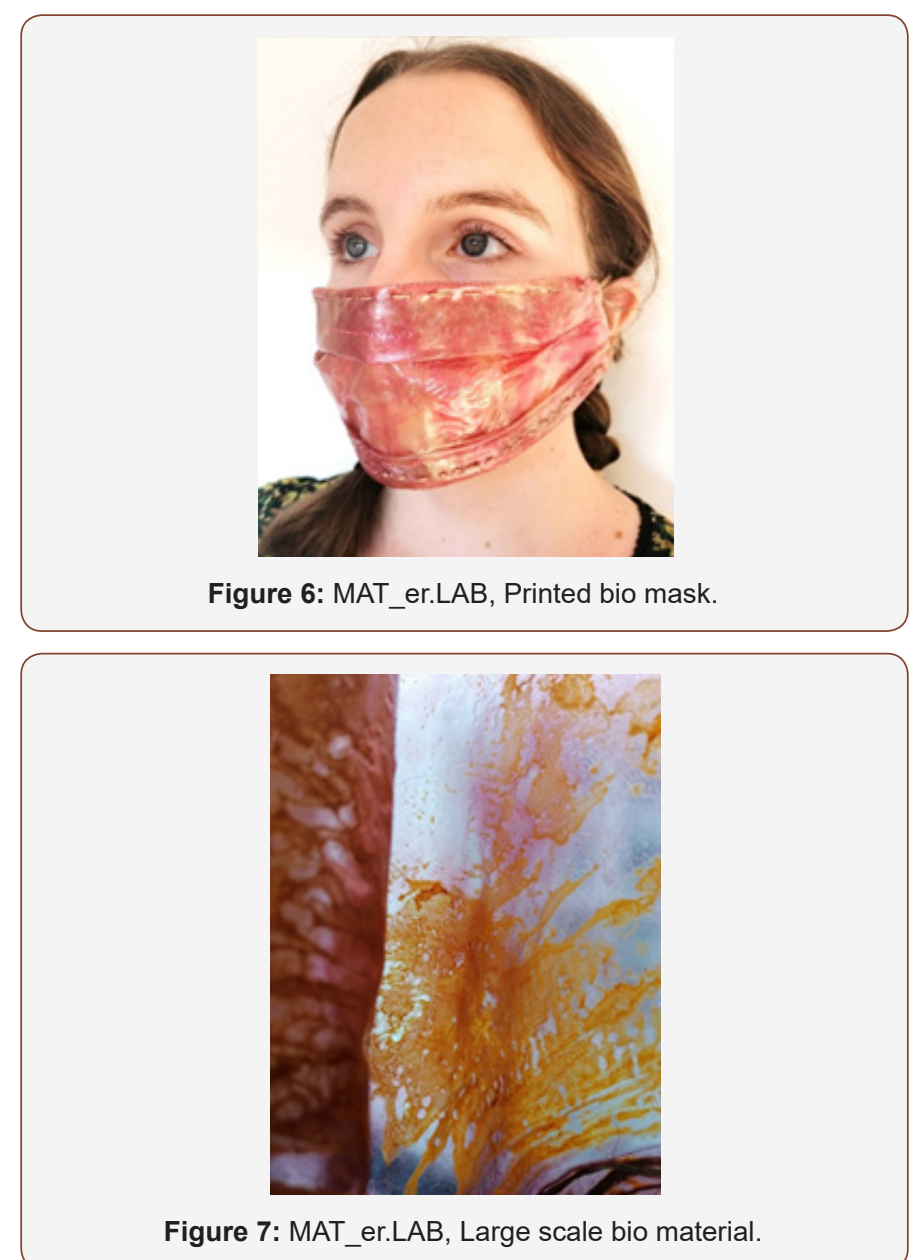

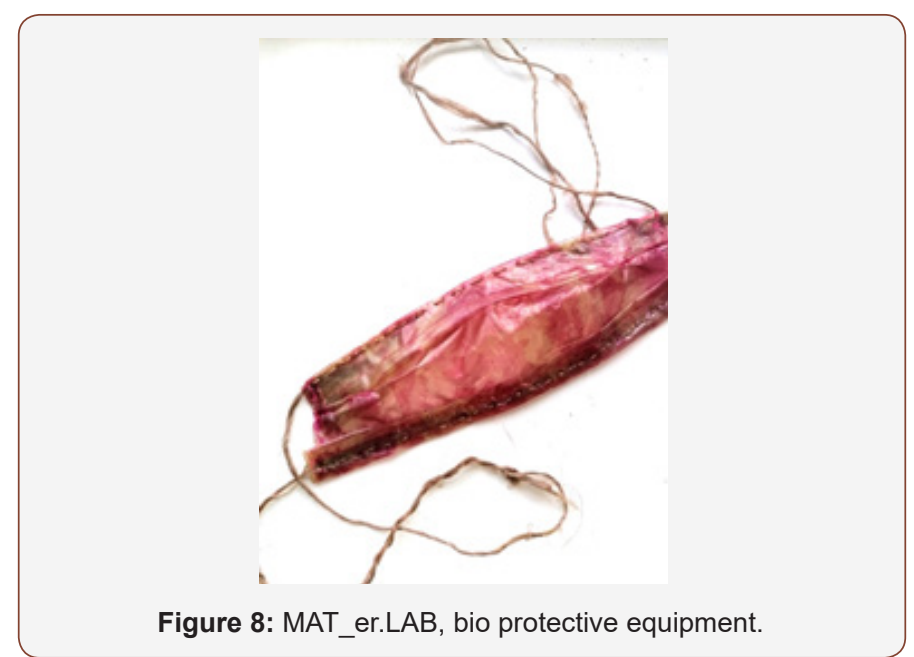

From a long-term perspective, re-iteration, one of the key aspects in Design Thinking, is the most effective way to approach a holistic outcome stable enough to withstand the harsh competition in creative industries. The ability to critically analyse and evaluate work is a valuable, not to say essential advantage for businesses of any size.

\section{Subject Learning and Personal Growth}

The project has established learning and teaching opportunities and approaches that promote the value of inter-disciplinary practice and knowledge exchange whilst connecting directly with student's interests, aspirations and future identities, identified as a key factor in engaging students in learning [6]. With that said, the valuable outcome of this new learning environment can be seen on multidimensional levels and is documented by 2 nd year Textile Design student Caitlin Agnew (2020) who states;

'The original learning experience which kick started my experience with MAT_er.LAB was the workshop run by KEA University. It focused on alternative material innovation and the use of natural materials. Personally, this was a new way of thinking for me at that time. Members of teaching staff (including the technicians) within the textile team encouraged me to pursue my investigation into these new materials. The staff supported me by sharing their own knowledge around sustainable practice and bio-design, helping me develops my practical work. Setting up a makeshift lab in the print room allowed me to engage flexibly with both the textile design environment and biomaterial innovation. It encouraged an interdisciplinary way of working. I was able to combine knowledge of textile design processes to further innovate new biomaterials.

Prior to this experience I was particularly engaged with printed textiles, particularly screen printing. I created 'bio' alternatives to traditional processes; this allowed me to incorporate purposeful aesthetic elements into the biomaterials. The exposure to the biomaterials workshops and continued support and encouragement from staff has allowed me to find an area of textiles which I am highly passionate about. It also allowed me to engage with other students from different faculties and courses. I have been able to share 
knowledge and discuss alternative applications for biomaterial innovations with students and staff from Product Design, Garment Tech, Fashion, Textiles and also prospecting students. I was able to expand my skill set and experience a more formal way of sharing information by co-leading a biomaterials workshop for textiles students. This was an experience I particularly enjoyed and hope to continue to expand on in the future. Overall, this experience has allowed me to identify an area of the textiles industry which I am interested in pursuing a career and practice in.'

There are three main areas which can be identified at the core of the impact which is driven through the MAT_er.LAB setting. Firstly, knowledge conceived through the laboratory can relate to many different ways of learning. As Orr S, et al. [7] (2018) describe, it can be absorbed unconsciously, through deliberations or interactions, but always as part of social worlds. Being exposed to the diverse backgrounds of participants knowledge is constantly questioned, recreated and shaped form various viewpoints offering a complex learning curve. The experimentation with materials creates reflective understanding for material properties which can be applied to course-related tasks, whether in fashion, textiles or architecture. Additionally, subject-based embodied knowledge can form the argumentation for an enriched aesthetical change when developed materials are brought in to evidence transformative design.

Secondly, the extended timeframe of material development results in on-going transformation, surprise and discovery. As nothing is static or limited, neither can the mind-sets be. The acceptance of change as a necessary, delightful and welcome aspect of discovery develops individuals more comfortable with uncertainty, and more prepared to work positively with and within it. An intimate understanding of cause and effect is gained, translating to greater confidence in other spheres of learning and interaction. Accepting that they are operating in a context that includes unforeseen consequences builds resilience. Collaboration rather than competition is nurtured. A positive experience although the 'product' might not be what was expected, can be transferred to other projects and academic modules creating a bigger acceptance of the process rather than the final result.

Furthermore, in a broader sense, it mirrors gained knowledge of benefitting from failing forward. With sensitive reactions to minimal changes in recipes where milligrams can have a huge impact on the overall experimental success, a wide range of unpredictable, playful failures are most likely to happen where attention to detail is lacking. Learning through the investigation of the unknown opens the much required mind-set to deal with the unexpected and nurtures thought processes outside the box. According to Dweck CS $[8,9]$ in contrast to the fixed mind-set where intelligence and ability are seen as being stable a 'growth mind-set [...] describes individuals who view their intelligence and ability simply as a basis for development and believe that challenges, including failure, are opportunities to develop their capacity for success through effort and practice.'
Taking this further it can be asked whether the participants of MAT_er.LAB already bring a growth mind-set when expressing interest in participating or whether it can also be learned simply through being exposed to a high risk-to-fail environment, detached from any judgmentor assessment. Considering the specificattributes when entering a flow state, described by Csikszentmihalyi M [10] as 'being completely involved in an activity for its own sake. The ego falls away. Time flies. Every action, movement, and thought follows inevitably from the previous one, like playing jazz. Your whole being is involved, and you're using your skills to the utmost.' Intrinsic motivation and commitment throughout the experimentation phase might reach heights of personal achievement. Moreover, it opens the discussion of whether the laboratory has the potential to ignite identity transformation when self-consciousness and goals are lost whilst participants are being immersed with individual tasks.

Thirdly, the specific collaborative approach of the MAT_er.LAB empowers social skills, communication being an important one to mention. Participants are encouraged to share resources and talent through the social construction of knowledge. This process often results in destabilising the frame of the sole learner to accommodate numerous visions and allows individuals to build a sense of community quite quickly and become more confident learners [11]. In 'Practicing Collaborative Action in Design. ' Sharon Helmer Poggenpol outlines that important problems and opportunities today tend to call for multiple perspectives, with decision-making shared among several people. She explains that 'Interdisciplinary is a set of dynamic forces for rejuvenation and regeneration, pressures for change, and the capacity for responsiveness' [12].

Participants are able to observe their own learning and the style of others and as a result, new relationships develop that encourage partnership working and peer learning. Participants engage more deeply in the tasks and through sustained shared struggles by partners; individuals begin to build confidence and strength in the cohort. As Bruffee KA identified in his 1986 essay 'Social Construction, Language and the Authority of Knowledge' the language of the community of peers was upheld over the individual self. This results in a new confidence in discussing diverse aspects of their collaboration and highlights the benefits accrued in the process of conceptualizing ideas from different knowledge domains and through different practices. This approach of learning in small groups is known to be very effective and also supports different learning styles of participants [13].

\section{Conclusion}

Only time will tell how design and fashion industries emerge from the current pandemic. There is real potential for seismic change, for those involved with design and education to start out again on a different path. However, such is the economic and psychological shockwaves of this experience the desire for the safety and stability of the familiar is going to be strong. In terms of materials, before Covid-19, it had felt that momentum was building 
in moving away from disposability, single-use thinking and the climate emergency had reached a level of public consciousness, but the vital role of personal protection equipment (PPE) will have an impact on this narrative.

With that being said, the vulnerability of individual fate has been dramatically and tragically exposed in this pandemic to an extent where barely anyone can ignore the huge human impact of economic decisions anymore. This, of course, includes the fashion industry as one of the biggest global economic drivers. As the impact tremendously relies on how leaders are aware of the value they either bring or take from society, in particular with influence on the individual, it needs to be assured that graduates bring the skills and attitudes to 'fulfil their potential and contribute to the well-being of their communities and the planet', as the OECD report asks for [14].

Micro cosmoses like MAT_er.LAB become learning catalysts and offer places for careful non-guidance to create radical thinkers. They have the potential to bring social change through action whilst reflecting the close, global ties between designs, make and end of use with a clear focus on humans and nature. The interdisciplinary and collaborative structure of this initiative breathes the spirit of circularity where diversity is inclusivity and waste becomes a powerful source to design with. MAT_er.LAB creates a new learning framework in form of a morphing island bridging all disciplines located in the Faculty of Art, Design and Media at BCU. It is an implemented vision in which sharing, responsible innovation is key. The overall success is to be seen in the fruitful incorporation of laboratory experiments into participant's individual course tasks but at the same time and maybe with even bigger importance, in personal growth which fosters resilience necessary for the many more life challenges to come.

How circular approaches, which thrive on collaborative practice and longevity, sharing strategies, will fare in a post-pandemic world that is likely to be initially highly cautious about interaction and exchange, remains to be seen. At some future point, there will be some sort of a new normality established, however it is desirable if the fashion world never reached this. As economic emergencies begin to take centre stage, there is a danger that this new 'status quo' would most likely means 'everything stays the same', still reliant on the old exploitative models. Questioning is needed to ensure a new status quo, when it finally arrives includes better solutions throughout the whole industry specifically with regards to the value of humans and the planet. What all creative industries clearly need is an on-going transition towards a circular system which, like a broader design thinking concept, will be re-iterated at all means and at all times.

\section{Acknowledgement}

None.

\section{Conflict of Interest}

Authors declare no conflict of interest.

\section{References}

1. OECD (2018) Skills for 2030.

2. Herodotou C, Sharples M, Gaved M, Kukulska-Hulme A, Rienties B, et al. (2019) Innovative Pedagogies of the Future: An Evidence-Based Selection. Frontiers in Education 4: 1-14.

3. Stahel WR (2019) The Circular Economy A User's Guide, Routledge, London, UK.

4. von Glaserfeld E (1987) Introduction to radical constructivism. Knowledge, language and reality 24: 198-212.

5. Dunne D, Martin R (2006) Design thinking and how it will change management education: An interview and discussion. Academy of Management Learning \& Education 5(4).

6. Hockings C, Cooke S, Bowl M (2009) Learning and teaching in two universities within the context of increasing student diversity: complexity, contradictions and challenges. David M (edt) Improving learning by widening participation. Routledge, London, UK.

7. Orr S, Shreeve A (2018), Art and Design Pedagogy in Higher Education, New York, USA.

8. Dweck CS (2000) Self-theories: Their Role in Motivation, Personality, and Development, New York: Psychology Press, USA.

9. Dweck CS (2006) Mindset: The new psychology of success, New York: Random House Publishing Group, USA.

10. Csikszentmihalyi M (1997) Creativity: Flow and the Psychology of Discovery \& Invention, New York: Harper Perennial.

11. Bruffee KA (1986) Social Construction, Language and the Authority of Knowledge. College English 8(8).

12. Poggenpol HS (2004) Design Intergrations - Research and Collaboration. Intellect. The University of Chicago Press, USA.

13. Fry H, Ketteridge S, Marshall S (2008) A handbook for teaching and learning in higher education: Enhancing academic practice. Routledge, London, UK.

14. OECD (2018) Learning Compass 2030. 